Journal of Sustainability Perspectives

journal homepage: https://ejournal2.undip.ac.id/index.php/isp/

\title{
Energy Saving and Renewable Energy production at University of Kashan, Kashan, Iran
}

\author{
Majid Monemzadeh ${ }^{1, *}$, Mahnaz Talebi-Dastenaei ${ }^{2}$ \\ ${ }^{1}$ Vice-Chancellor for Research, University of Kashan, Kashan, Iran \\ ${ }^{2}$ Expert on University Ranking Systems, University of Kashan, Kashan, Iran \\ * corresponding author: monem@kashanu.ac.ir
}

Article Info

Received:

15 March 2021

Accepted:

25 May 2021

Published:

1 August 2021

DOI:

Presented in The $6^{\text {th }}$ International (Virtual)

Workshop on UI GreenMetric

World University Rankings

(IWGM 2020)

\begin{abstract}
University of Kashan was founded in 1974 and is the oldest


E) climate is classified as a hot and dry by the Köppen-Geiger system. This climate causes a large amount of energy consumption for University at springs and summers. On the other hand, it means that sun is shining strongly for more than 6 months and University of Kashan has been working on some solutions to use solar energy and decrease dependency on the old fossil-fuel energy system. The current paper studies some of the main activities of University of Kashan on Energy Saving and Renewable Energy Production programs such as CCHP plant (The first Combined Cool, Heat, and Power plant in Iran), using solar panels and energy-efficient appliances.
\end{abstract}

\section{Keyword:}

Energy, renewable energy, solar, plant, University of Kashan, Iran

\section{About City of Kashan}

Kashan is an ancient historical city with an outstanding record in many different aspects of Persian Civilization, culture, and development dating back to 7000 years ago. Archaeological discoveries in the Sialk Hillocks, which lie $4 \mathrm{~km}$ west of Kashan, reveal that this region was one of the primary centers of civilization in pre-historic ages. Hence, Kashan dates to the Elamite period of Iran. The Sialk ziggurat still stands today in the suburbs of Kashan after 7,000 years [1].

Many scholars, scientists, philosophers, and thinkers from this city have contributed to the development of its Islamic history. There are many historical sites in Kashan, which include some of the best and most attractive classical architectures in the historical housing of Iran. People of Kashan are famous for their devotions to religion, culture, and literature. With its incredible history of workmanship development in many professions, including 
textile, carpet, ceramics, essential oils and medicine, architecture, copper, iron, steel, and lately in car, motorcycle, cement, etc. Kashan offers an incredible history of urbanism most of which are to be explored and it is no wonder that it is referred to as one of the oldest cities in the world.

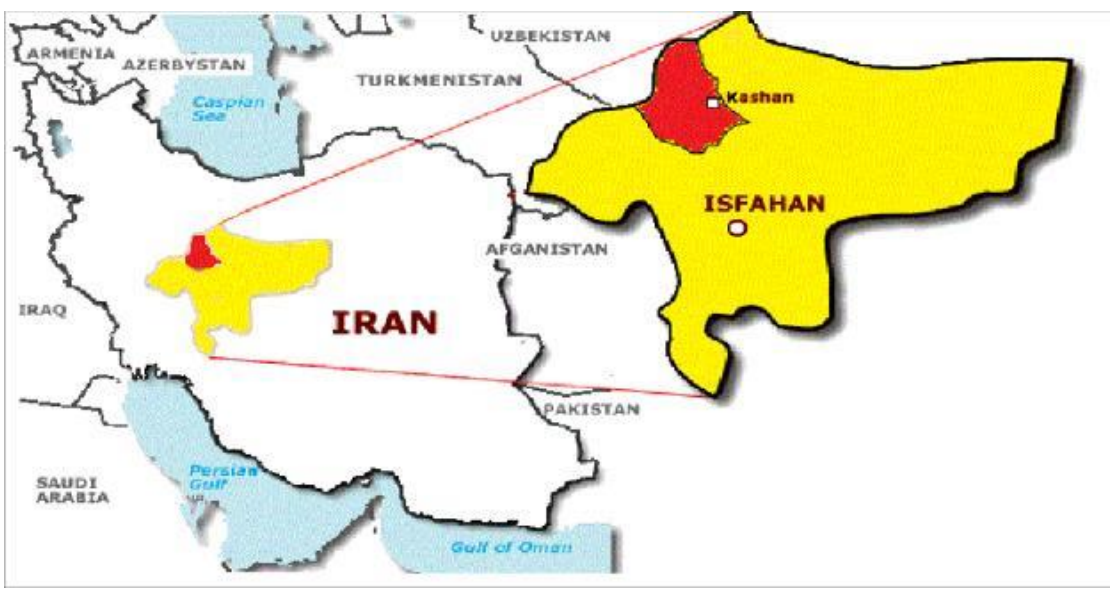

Figure 1. The location of Kashan on the Iran map

\section{Climate of Kashan}

Kashan ( $33^{\circ} 58^{\prime} 59^{\prime \prime} \mathrm{N} / 51^{\circ} 25^{\prime} 56^{\prime \prime} \mathrm{E}$ ) climate is classified as BWhsa by the KöppenGeiger system, with a hot and dry climate and virtually no rainfall during the year [2], where $B$ is dryness; $W$ is the intensity of dryness where the average annual rainfall (13.5) is lower than the average annual temperature in ${ }^{\circ} \mathrm{C}$ (19.7). $\mathrm{h}$ shows that the average annual temperature is above $18{ }^{\circ} \mathrm{C}, \mathrm{s}$ is the sign of rain in the cold seasons or the winter and a show that the temperature in the warmest month of the year is above $22{ }^{\circ} \mathrm{C}$ [1]. According to DeMarttone climatic classification, which is based on the dryness coefficient and considers two factors of temperature and rainfall, the climate of Kashan is dry with a dryness coefficient of 4.5 .

\section{About University of Kashan}

University of Kashan was founded at first as an institution of higher education in 1973. It began its activities in October 1974 by 200 students of mathematics and physics. In 1989 more academic fields were added and the institution continued its activities as Kashan Teacher-Training University under the supervision of the Ministry of Science. In 1994, by offering engineering disciplines, this university was acknowledged as a main university by the Ministry of Science. In 1995 College of Architecture and Arts was added to the university with an emphasis on the local needs, art and industries of the region. Faculty of Chemistry, as the fifth college after Science, Humanities, Engineering, Architecture, and Arts, was founded in 2008. Currently, University of Kashan, within the boundary of 530 hectares and with 80000 square meters of infrastructure (building), in addition to educational campuses, sports facilities, dormitory complexes, restaurant complex, amphitheatres, green spaces, mosque, study halls, and the healthcare center provides leisure, services, and comforts to the students. Besides the five mentioned colleges, there are three active research institutes including Nano Technology, Natural Essential Oils, and Energy and three Research Centres including Kashan studies, Carpet, and Astronomy that contribute to the fact that University of Kashan in recent years has been among the top ten universities in Iran. Accommodating 
more than 7500 students in 50 disciplines of undergraduate, graduate and postgraduate levels and having about 300 full-time faculty members [3].

\section{University of Kashan's Activities About Energy Saving and Renewable Energy Production}

- Holding some Conferences and workshop for professors, students, and staff on Energy Saving and Renewable Energy production

- Holding the Virtual Training Course on Energy Conservation. (Number of participants: 350)-2019

- Holding the Second National Conference of Energy and Architecture

- Holding the International Conference of Energy and Architecture (using modern equipment in buildings)

- Holding the conference about Aspects of Green architectures in Historical Houses of Kashan [4].

\subsection{Example of courses/modules related to energy (University of Kashan, Kashan)}

Table 1. Courses/modules related to energy

\begin{tabular}{|l|l|}
\hline Courses/Modules & Faculty/ Department \\
\hline - Energy Engineering & \\
- Bntegration of heat and power & \\
- Energy audits in the chemical industry & Natural Resource Faculty \\
- Energy recovery in industries & \\
- Solar systems & \\
- Renewable Energy & The Department of Biology and \\
- energy and Environment & Civil Engineering \\
- Energy systems & \\
\hline - Energy & \\
- Energy management & \\
- Gas distribution and transmission & \\
- Refining processes & \\
- Industrial catalyzers & \\
- Chemical industry safety & \\
- Heating and cooling in the chemical & \\
- industry & \\
- Rater and wastewater treatment of the & Engineering \\
- Environmental biotechnology & \\
- Bodeling and Simulation of Biological & \\
\hline
\end{tabular}




\subsection{Renewable energy production inside the campus}

University of Kashan is one of the pioneers in designing and making the renewable plant in Iran. University of Kashan can supply more than $70 \%$ of its energy consumption.

A natural gas generator generates power generation but recycles it instead of the heat generated by the generator in the CCHP system and is used to warm the building in winter. This heat supplies the absorbent chiller in the summer and the production of chiller is achieved through this. Electricity generated by this center is injected into and sold to the electricity grid. The heat recovery in this system is equivalent to 60,000 cubic meters of natural gas per month. Through this saving, more than 900 million Rials will be donated to the national economy annually based on the export rate of gas to Turkey.


Figure 2. The first Combined Cool, Heat and Power plant (CCHP) in Iran (University of Kashan, Kashan)

\subsection{Energy efficient appliances usage are replacing conventional appliances}

In recent years, Kashan University has made great efforts to use sunlight as a source of energy. Also, the production and use of renewable energy and the optimization of energy tools have been other priorities of this university. 


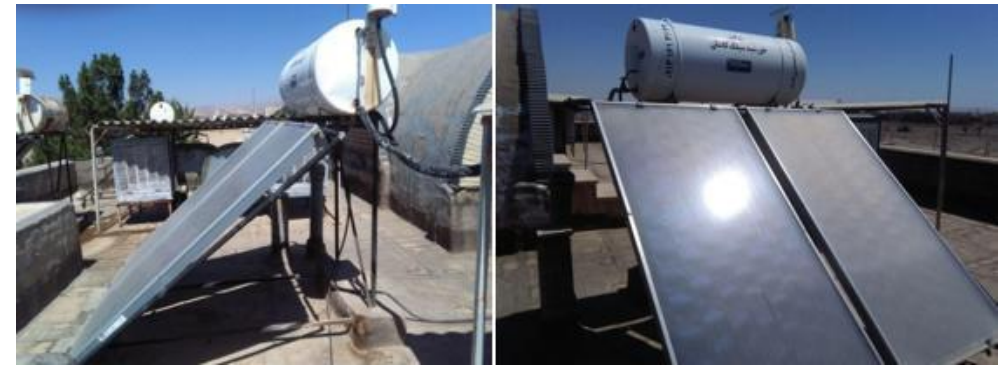

Figure 3. Installation of solar water heater for the supply of heated water for 14 buildings at University of Kashan, main campus.

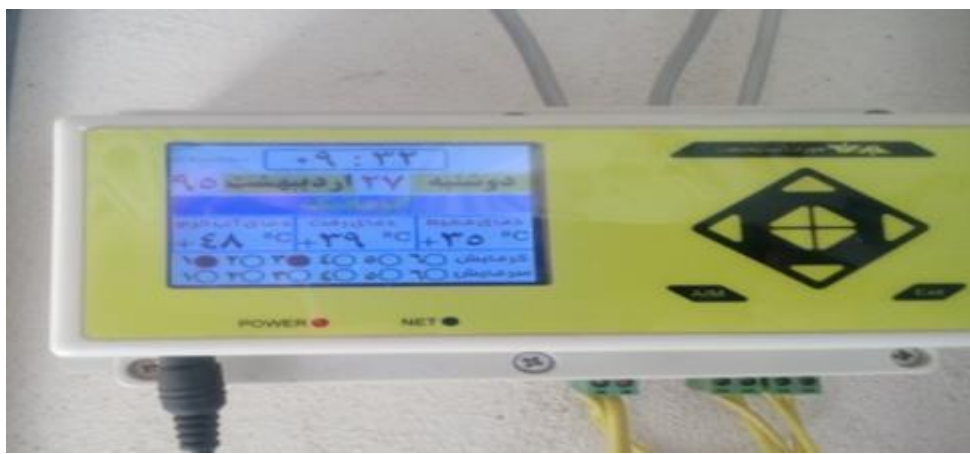

Figure 4. Intelligent control of the engine room (This system controls the volume of the burners by getting indoor and outdoor temperatures), University of Kashan, Iran

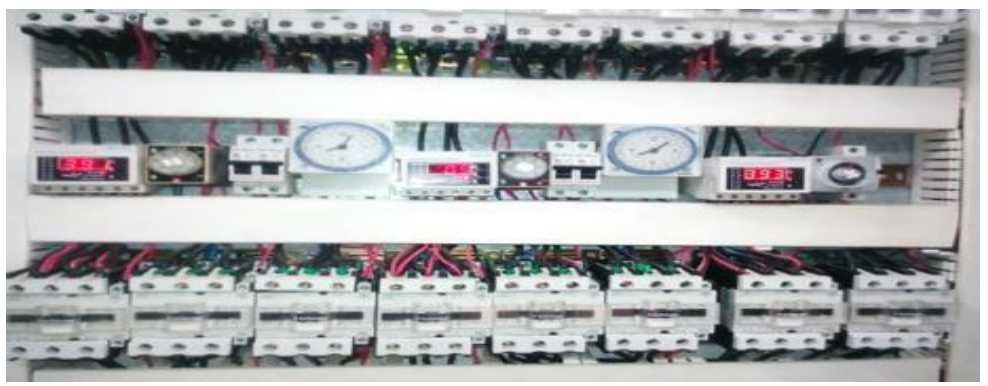

Figure 5. Optimization of the operating time of engine rooms and equipment of buildings, University of Kashan

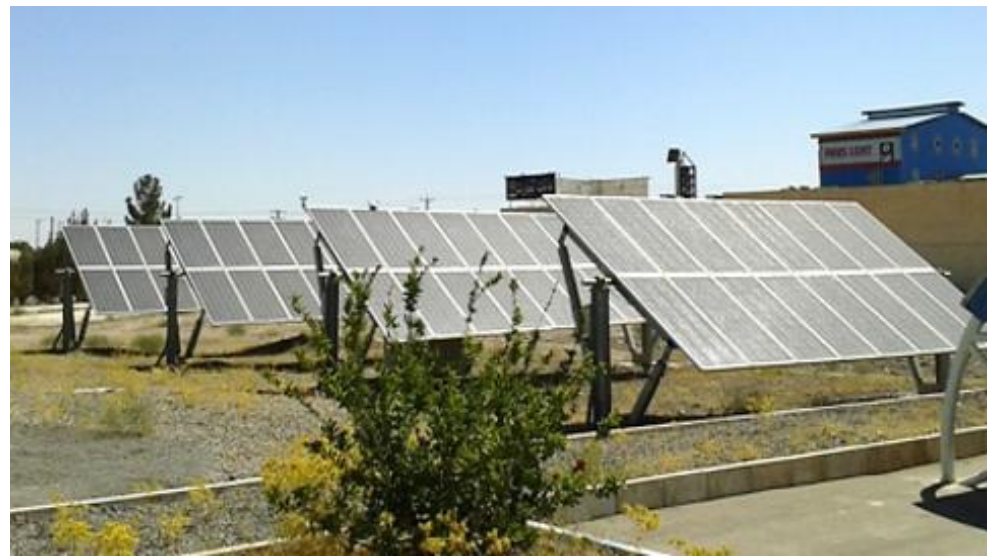

Figure 6. Using 20 kilowatts of solar energy for lighting part of the main campus of University of Kashan 


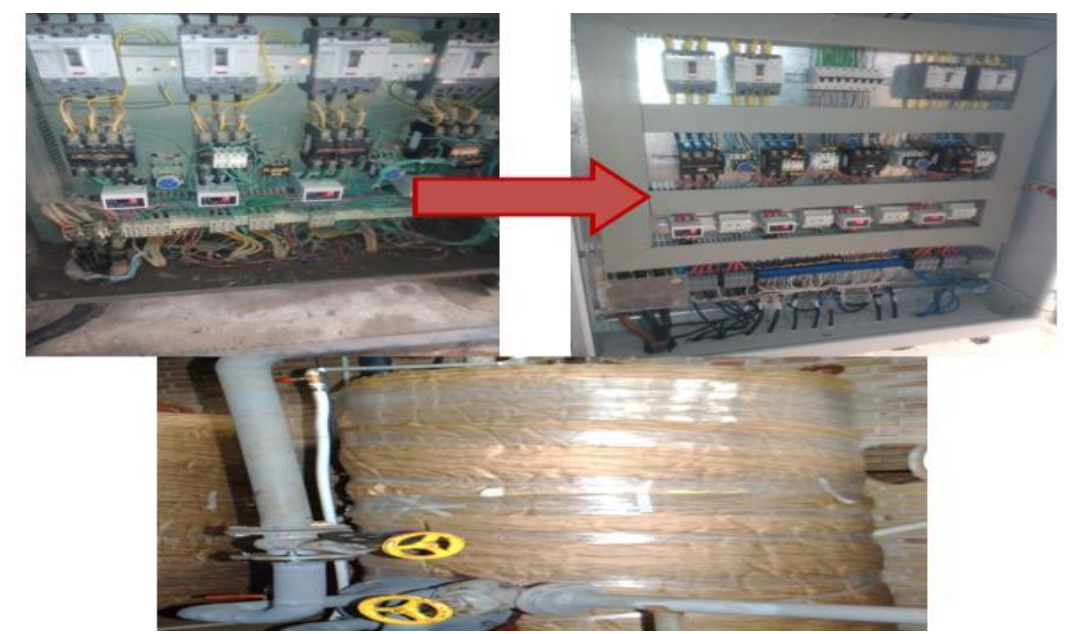

Figure 7. Renovation of some of the worn electrical installations, such as power boards and replacement of worn-out engines, University of Kashan

\section{Conclusion}

In the current study, we talked about Energy Saving and Renewable Energy production at University of Kashan. At first the city of Kashan was introduced; Kashan is a city in the northern part of Isfahan province and is well known as a historical city with many historical sites. After brief introduction of University of Kashan, we focused on University of Kashan's activities about Energy Saving and Renewable Energy production, such as Holding some Conferences and workshop for professors, students, and staff on Energy Saving and Renewable Energy production; Holding the Virtual Training Course on Energy Conservation; Holding the conference about Aspects of Green architectures in Historical Houses of Kashan. It is worth mentioning that there are an increasing number of courses related to Energy and renewable energy production as the main courses taught in engineering faculty and Natural resource faculty at this University. Having the first renewable plant in Iran is the main distinguished feature of University of Kashan in the Renewable energy production's topic. CCHP (The first Combined Cool, Heat, and Power) plant is a natural gas generator generates power generation.

\section{References}

1. Jomehpour, M. (2009). Qanat irrigation systems as an important and ingenious agricultural heritage: a case study of the qanats of Kashan, Iran. International Journal of Environmental Studies, 66(3), 297-315.

2. Korsavi, S. S., Zomorodian, Z. S., \& Tahsildoost, M. (2018). Energy and economic performance of rooftop PV panels in the hot and dry climate of Iran. Journal of Cleaner Production, 174, 1204-1214.

3. Monemzadeh, M. (2018). Water conservation and water recycling program implementations at University of Kashan. E3S Web Conf. The 4th International Workshop on UI GreenMetric World University Rankings (IWGM 2018), 48, 05003.

4. Kashanu.ac.ir/en 